\title{
Introduction of a new teaching method to support Professional Identify Formation in medical students
}

\section{Salome Scholtens ( $\sim$ s.scholtens@umcg.nl )}

Universitair Medisch Centrum Groningen https://orcid.org/0000-0002-0651-5203

Hedwig Boer

Universitair Medisch Centrum Groningen

Margreet Smit

Universitair Medisch Centrum Groningen

Jan Jacob Stam

Bert Hellinger Institute Netherlands

Pieter C Barnhoorn

Antje Schmitt

Rijksuniversiteit Groningen

Joke Fleer

Universitair Medisch Centrum Groningen

\section{Research article}

Keywords: Professional Identify Formation, tacit knowledge, socialisation, experiential learning, social system

Posted Date: November 16th, 2020

DOI: https://doi.org/10.21203/rs.2.12524/v2

License: (c) (i) This work is licensed under a Creative Commons Attribution 4.0 International License. Read Full License 
Introduction of a new teaching method to support Professional Identify Formation in medical students

SHORT TITLE: a new teaching method to support PIF 


\begin{abstract}
Professional Identify Formation is regarded as fundamental to medical education. It involves a process of socialisation where knowledge is often acquired unconsciously via social interaction. Concrete teachings to support and mediate this socialisation process are difficult to implement, because of the implicit nature of the transferred knowledge. Before effective reflection can start, the implicit knowledge has to become explicit. The authors argue that training based on the Systemic Constellation method may be a promising way to support Professional Identify Formation among medical students, by increasing students' awareness of their own socialisation process and the implicit knowledge that they have acquired. By visualising their social context with a group of students, the method is effective in making explicit the social context and the values, beliefs, perspectives that are present. This creates the possibility to discuss these values, beliefs, perspectives and explore differences, and stimulates individual and group reflection. The method is already widely used in business settings, but not yet in the medical education setting. This article presents how this new training method was implemented in the undergraduate medical curriculum of the University of Groningen, the Netherlands, and discusses its feasibility, acceptance and perceived usefulness by medical students.
\end{abstract}

Keywords: Professional Identify Formation, tacit knowledge, socialisation, experiential learning, social system 


\section{Practice points}

- Professional Identify Formation is mediated through socialisation, an often unconscious process.

- The knowledge that is acquired through this socialisation process is implicit, experiential and requires social interaction, and is therefore difficult to translate into concrete teaching practices.

- Teaching to support the unconscious aspects of Professional Identity Formation may optimise the process.

- The authors argue that training based on the Systemic Constellation method may be a promising way to support Professional Identify Formation among medical students, by increasing students' awareness of their own unconscious socialisation process and of the social systems that they are part of.

- Implementation of training based on the Systemic Constellation method for undergraduate students in the medical education setting was feasible, and accepted and perceived as useful by a majority of the students. 


\section{Introduction}

Professional Identify Formation (PIF) is regarded to be a fundamental aspect of medical education (Cooke et al., 2010; Cruess et al., 2015; Jarvis-Selinger et al., 2012). Where identity formation is a continuous process that happens in medical school, during residency and beyond (Hafferty \& Franks, 1994; Leedham-Green et al., 2019; Witman, 2014), for medical students to develop a Professional Identity, support in this process is desired and education is one of the important tools in this process (Cruess et al., 2015; Goldie, 2012).

Professional identify formation is a process achieved through socialisation, which is often an unconscious process within a social context (Cruess et al., 2015). Much of the knowledge essential to develop a Professional Identify is therefore tacit knowledge (Cruess et al., 2015; Cruess et al., 2019). Tacit knowledge can be defined as the collective, implicit knowledge, that consists of habits, beliefs, values, social structures, and 'how we do things here' (Lam, 2000; Sturmberg \& Martin, 2008). While the establishment of a cognitive knowledge base on PIF among learners is relatively easy to implement in medical education, supporting and mediating the acquisition of the tacit knowledge that shapes the professional identify is more difficult, because of the implicit nature of this type of knowledge (Lam, 2000).

Literature suggests the use of experiential learning and guided reflection with mentors and role models as effective means to influence PIF in an educational setting (Goldie, 2012; Wald, 2015; Cruess et al., 2019; Yazdani et al., 2019). However, before learners can reflect on their professional identify, teaching must first allow a learner to become consciously aware of their socialisation process and the tacit knowledge that they have 
already acquired unconsciously in this context (and are still acquiring). The implicit knowledge needs to become explicit. Up to now, concrete, practical examples of implementation of such teachings are scarce. Without good teaching methods that address the tacit aspects, the process of PIF might develop in a suboptimal way. A promising teaching method to make learners more aware about their tacit knowledge of their social context and socialisation is the Systemic Constellation method (Arnold \& Prescher, 2017; Burchardt, 2015; Kopp \& Martinuzzi, 2013; Weinhold et al., 2014). This experiential learning method in groups stimulates reflection for the individual and the group (more details on the method will follow). The method is based on a process of zooming out from the individual level to the larger social system level and encompasses a live visualisation of the elements of a social system in a spatial way. Through the visualisation of a social context with a group, the method is effective in making explicit the social context and the values, beliefs, habits, perspectives that are present. This creates the possibility of discussing these values, beliefs, habits, perspectives and of exploring differences. A systemic constellation training is often performed with a group of 10-30 learners led by a trained facilitator. The method is already widely used in business settings for transformation processes, team development, and leadership training (Burchardt, 2015; Weinhold et al., 2014) and has also been applied in education (Kopp \& Martinuzzi, 2013).

We adapted the method into a form that would fit within the medical education setting. From 2017 we offered training using the Systemic Constellation method in the medical curriculum of the University of Groningen, the Netherlands, as part of an educational track on leadership development (Fleer et al., 2017). Because it has been emphasised to 
start education addressing PIF early in the curriculum (Cruess et al., 2019), we started with undergraduate medical students. To our knowledge, the Systemic Constellation method has currently not yet been used in undergraduate or graduate medical curricula. In this article, we propose the Systemic Constellation method as a teaching method to support PIF, discuss implementation of the method in a large group of undergraduate medical students and provide practical details about the training for teachers. In addition, we reflect on our evaluation with the students to gain more insight in the application of this new method in the medical education setting.

\section{The Systemic Constellation method}

The Systemic Constellation method was originally developed in Germany for psychotherapy (focused on the family system) and later applied to other social systems such as organisations (Weinhold et al., 2014). 'Social system' refers to any group of people (e.g. colleagues, team members, organisations). The Systemic Constellation method has a strong basis in social constructionism and assumes that people have a perception of their social reality which results from a largely unconscious socialisation process and is influenced by the social systems which they are part of (Gminder, 2005; Weinhold et al., 2014). In line with the concept of habitus (Bourdieu, 1992) the method acknowledges that individuals are part of many different, smaller or larger social systems at the same time, all with their own (conflicting) habits, values, interrelations, and structures. The method builds on the assumption that people have acquired tacit knowledge about these social systems, related to the 'Unconscious Acquisition' in socialisation presented by Cruess et al. (2015, Figure 2, p. 4). 
The method makes learners more aware of their own social context and their tacit knowledge about it, by visualising the social system the learner is part of. To this end, a spatial arrangement of elements (using people or objects) representing elements of the social system is used, also called 'systemic constellations' (Figure 1). Elements can be a person, function or role in the social system (e.g. the supervisor or a nurse), groups or stakeholders (e.g. patients), or concepts or societal aspects (e.g. insurance). In this way, the social system is made visible and tangible. The structures of the social system, the inter-dependencies between different elements and different perspectives (e.g. of the perspective of an external observer or of someone else within the group) are explored with the learner and the group.

This spatial visualisation relies on learners' tacit knowledge about their social systems and makes this implicit knowledge explicit. It makes use of the human ability to interpret social space or interpersonal distance and perceive the social meaning from it (Hall, 1966; Lloyd, 2009). The method is often applied in a workshop setting with 10 to 30 participants and a trained facilitator. The facilitator guides the process and stimulates individual and shared reflection. A detailed procedure is presented in Appendix 1.

[Figure 1 near here]. 


\section{Implementation of the training for undergraduate medical students}

\section{Aim of the training}

The aim of the training is to support PIF by providing learners an opportunity to increase their:

1) awareness of the tacit source of knowledge that they already have about their social context in general (implicit knowledge becomes explicit);

2) the ability to use this knowledge so that they become more aware of the social context they are currently in and the socialisation processes that are present;

3) the ability to reflect on their socialisation and on their social context (and the beliefs, norms, values that are present) with other students.

\section{Details of the students}

The training was offered to about $3003^{\text {rd }}$-year undergraduate medical students. Medical training in the Netherlands lasts 6 years and consists of a three-year bachelor program and a three-year master program. In general, the bachelor has a focus on gaining theoretical knowledge, while the master has a focus on developing skills and consists mainly of internships. Thus, the students in our training had only had a minimum of clinical experience during the training.

\section{Setting and timing}

The Systemic Constellation training was held at the medical faculty of the University of Groningen, the University Medical Centre Groningen, the Netherlands over the course of 2 weeks. It took place in regular tutor rooms, where the tables and chairs could be 
removed. The training was scheduled during the second semester, which is the last

semester before the $3^{\text {rd }}$-year bachelor students start their medical internships. The training was compulsory and part of the educational track on leadership and professional development.

\section{Trainers}

We worked with trainers appointed at the medical faculty and acquainted with the medical education setting, who were trained in the Systemic Constellation method during a 4-day training program at the Bert Hellinger Institute in the Netherlands. Every year, the training was practiced with all trainers during a one-day practice day in which students also participated.

\section{Outline of the training}

The 2-hour training was developed in 2017 in cooperation with students, teachers and experts on the Systemic Constellation method from the Bert Hellinger Institute in the Netherlands. To allow the students to link their learnings and insights to their current situation and to increase direct applicability, we focussed the training on a social system that the students were all currently part of, i.e. their research project team. At the time of the training, the students worked in groups of 2-5 students on a research project for a semester. Per training session, 2-4 research project teams were included, leading to in total 10-15 students per session. The training focused on the research project team; no personal issues of the students were addressed during the training sessions. Details of the complete training can be found in Appendix 1. In brief, for each research project team a 
current social context was visualised, using students representing relevant elements (the constellation). Subsequently, the students of the research project team placed themselves in the constellation, relative to each other and the elements. The group reflected on the constellation as a whole and on the observations and perspective of the persons in it, guided by the trainer. This opened up the students' implicit beliefs associated with the social context and the structures and relations in it. It enabled these beliefs and perspectives to become explicit so that they could be discussed within the group.

\section{Evaluation with the students}

\section{Questionnaire}

In 2019 , the students evaluated the training by completing an anonymous, digital questionnaire, implemented by using Qualtrics that could be accessed by smartphone, tablet, or laptop. The link to the questionnaire was emailed to the students enrolled for the training, the night before the training. The students were asked to complete the questionnaire directly after the training. All students were informed about the aim of the evaluation and gave informed consent. The evaluation was approved by the Ethical Committee of the Department of Psychology at the University of Groningen.

The questionnaire contained questions on age, gender and familiarity with the method (Appendix 2). Furthermore, the questionnaire consisted of four elements: general feedback, timing, overall satisfaction and an open question. General feedback was assessed in three items: 'I liked the training', 'The training gave me useful insights or help with the teamwork' and 'The training set-up was clear to me', with a 7-scale answer 
category ranging from 'strongly disagree' to 'strongly agree'. Timing was assessed by the question: 'The training came .... during my training', with a 3-scale answer category being 'too early', 'at the right moment', 'too late'. Overall satisfaction with the training was assessed by the question 'How satisfied were you with the training, on a scale from 0 to 100 ?'. In an open question students were asked about their suggestions on how the training could be improved and what the students liked about the training. Based on the answers to the open questions, answer categories were defined and the answers were coded independently by two researchers. In case of discordant coding, the coding was discussed until consensus was reached. The quantitative data were analysed using SPSS (IBM SPSS Statistics for Windows, Version 23.0).

\section{Results and feedback}

The training was attended by 308 students, of whom $223(72 \%)$ completed the evaluation questionnaire. Almost one third of the students was male $(31.4 \%, \mathrm{~N}=70)$ and the mean age was 21.3 years ( $\mathrm{SD}=1.6$ years). A majority of the students, liked the training $(64.1 \%$, $\mathrm{N}=143), 17.0 \%(\mathrm{~N}=38)$ was neutral and $18.8 \%(\mathrm{~N}=42)$ disliked the training (Table 1). The training gave useful insights with regard to their teamwork to 148 students $(66.4 \%)$ and came at the right moment according to 164 students $(77.0 \%)$. Overall, satisfaction of the students with the training got a mean score of $67.6(\mathrm{SD}=16.0)$ on a scale of 0 to 100 . As suggestions for improvement 'Prepare the students better for the training' and 'Explain more about the training' was mentioned most often (Table 2). On the open question 'What did you like about the workshop?' 136 students provided answers. More than half of the students liked the visualisation of the social dynamics, the new insights 
and new perspectives $(54.4 \%, \mathrm{~N}=74)$. Also, the good atmosphere $(11.8 \%, \mathrm{~N}=16)$ and the interactive method was appreciated by the students $(14.7 \%, \mathrm{~N}=20)$.

[Table 1 and 2 near here]. 


\section{Discussion}

The implementation of teaching to support and guide PIF can be difficult. PIF builds on tacit knowledge and values that are acquired in an unconscious socialisation process (Cruess et al., 2015). In the socialisation process, knowledge and values are transferred to students from the medical education community. To convert this acquired tacit knowledge into explicit knowledge is key (Yazdani et al., 2019). This article presents a new teaching method, the Systemic Constellation method, to enable students to become aware of their tacit knowledge of their social context. The method could be successfully implemented for undergraduate students with no prior experience with constellations in the medical education setting. The method was accepted and considered as useful by the majority of the students.

To our knowledge, this is the first time that the Systemic Constellation method has been applied in an undergraduate medical education setting. Because of the large number of students and implementation in three successive years, we have gained ample experience with the method.

For most of the students in this sample, the training was a first encounter with experiential learning in general and with the Systemic Constellation method in particular. As undergraduate students they are used to cognitive learning and often receive teaching in the form of lectures. This might explain the critical appreciation of some of the students, but also their suggestions to explain more about the training. Furthermore, we anticipated that the training might come too early, because the students had no experience with working in the clinical setting yet. However, the majority of the students indicated that the timing of the training was appropriate. This finding supports the idea of starting 
this type of training in the undergraduate phase, and of linking the training to a social system the students are currently engaged in, i.e. research project team.

With this training, we offered the students a new experience, created a setting for experimenting with different perspectives on their social context and socialisation, and stimulated reflection. A strength of the Systemic Constellation method is that it, literally, makes the social context explicit by visualizing the system using the spatial arrangement of representatives (the other students) (Kopp \& Martinuzzi, 2013). This allowed all students to have a look at the same external image of the social context as a representation of their own internal images and view it from different perspectives. Importantly, it opens up their tacit knowledge attached to this social context. By having the training with other medical students, it was a shared experience which allowed for personal reflection as well as collaborative learning and shared reflection, which are important elements in the process of PIF (Cruess et al., 2019).

The aspect of visualisation and externalising implicit inner images shows resemblance with methods like Soft Systems Methodology, where Rich Picture Building by means of drawing is the first step in exploring the problem (Checkland, 2000). An important difference is that the Systemic Constellation method is focused on the social context of the learners and that it is a shared experience.

The large number of students that reported to have gained useful insights, and the specific appreciation of the visualisation and change of perspective mentioned by various students, supports the assumption that the Systemic Constellation method can be useful for students to get a new view on the social context they are currently in and activate reflection. 
A limitation of the study is that we could only evaluate reactions of the students and not include other levels of training evaluation outcomes (such as effectiveness) and actual contribution to PIF (Arthur. et al, 2003). Via the open questions, we only got a scant view on the reasons behind the level of appreciation and perceived usefulness. Further research is needed to gain more insights into these underlying reasons.

This article presents a new method for developing awareness among medical students of their social context and their socialisation process, and the tacit knowledge that they have of it. It provides a first step to evaluate the acceptability and perceived usefulness of this method in this setting. With the results from this implementation we can proceed with training sessions based on the Systemic Constellation method and have ample starting points for improvement, such as providing students with a preparatory assignment in advance, or explaining more clearly why we offer this training. Now we have a training protocol that is feasible and acceptable, the next step is to set up an in-depth evaluation study to assess outcome effect and contribution to the acquisition of a professional identity. In order to make PIF a conscious process which the student can reflect on, repeated training and connection with the broader medical system is required. (Frenk et al., 2010; Larsen, 2019). Therefore, we aim to embed the training in the medical curriculum at different stages. This way, medical professionals can become equipped from an early stage with an understanding of their social context and the impact of the socialisation process, and develop the reflective attitude essential for PIF. 


\section{Acknowledgments}

We would like to show our gratitude to all trainers who contributed to the development of the training or who were involved as a trainer during the training. We thank Hendertje Wierenga for her efforts in the data collection and support in preparation of the training, and Maya Schroevers for the critical review of the concept and the manuscript.

\section{Declaration of interest}

The author reports no conflicts of interest in this work.

\section{Author contribution}

SS, JJS, MS, HB designed and gave the training. JF, AS, and SS designed the evaluation and the data collection. AS supervised the data collection. SS wrote the manuscript with support from PCB, AS and JJS. SS and HB performed the data analyses. JF supervised the project. All authors discussed the results and contributed to the final manuscript. 


\section{References}

Arnold, R., \& Prescher, T. 2017. From transformative leadership to transformative learning. In: Transformative learning meets bildung. A. Laros, T. Fuhr \& E. W. Taylor (eds.), . Sense Publishers

Arthur, W., Bennett, W., Edens, P. S., \& Bell, S. T. 2003. Effectiveness of training in organizations. Journal of Applied Psychology, 88(2): 234-245.

Bourdieu, P. The logic of practice. New edition. Translated by Richard Nice. Polity Press, Oxford; 1992.

Burchardt, C. 2015. Chapter 9. business coaching and consulting - the systemic constellation approach in business. In: Modelling and management of engineering processes. e. a. Schabacker M. (ed.), . pp. 101-112

Checkland, P. (2000). Soft systems methodology: A thirty year retrospective. Systems Research and Behavioral Science, 17(S1), S11-S58.

Cooke, M., Irby, D. M., \& O'Brien, B. C. 2010. Educating physicians: A call for reform of medical school and residency. San Francisco.: John Wiley and Sons.

Cruess, R. L., Cruess, S. R., Boudreau, J. D., Snell, L., \& Steinert, Y. 2015. A schematic representation of the professional identity formation and socialization of medical students and residents: A guide for medical educators. Academic Medicine, 90(6): 718-725. Cruess, S. R., Cruess, R. L., \& Steinert, Y. 2019. Supporting the development of a professional identity: General principles. Medical Teacher, 41(6): 641-649.

Frenk, J., Chen, L., Bhutta, Z. A., Cohen, J., Crisp, N., Evans, T., Fineberg, H., Garcia, P., Ke, Y., Kelley, P., Kistnasamy, B., Meleis, A., Naylor, D., Pablos-Mendez, A., Reddy, S., Scrimshaw, S., Sepulveda, J., Serwadda, D., \& Zurayk, H. 2010. Health professionals for a new century: Transforming education to strengthen health systems in an interdependent world. The Lancet, 376(9756): 1923-1958.

Goldie, J. 2012. The formation of professional identity in medical students: Considerations for educators. Medical Teacher, 34: e641-e648. 
Gminder, C. 2005. Nachhaltigkeitsstrategien systemisch umsetzen. eine qualitative exploration der organisationsaufstellung als managementmethode. (Doctoral dissertation, University of St. Gallen, Germany).

Hafferty, F. W., \& Franks, R. 1994. The hidden curriculum, ethics teaching, and the structure of medical education. Academic Medicine, 69(11): 861-871.

Hall, E. T. 1966. The hidden dimension. New York, USA: Doubleday.

J. Fleer, C van Bruggen, J de Jeu, \& J Borleffs. 2017. Ontwikkel leiderschap al in de bachelor. Medisch Contact (in Dutch), (06)

Jarvis-Selinger, S., Pratt, D. D., \& Regehr, G. 2012. Competency is not enough:

Integrating identity formation into the medical education discourse. Academic Medicine, 87(9): 1185-1190.

Kopp, U., \& Martinuzzi, A. 2013. Teaching sustainability leaders in systems thinking. Business Systems Review, 2(2): 191-215.

Lam, A. 2000. Tacit knowledge, organisational learning and societal institutions: An integrated framework. Organization Studies, 21(3): 487-513.

Larsen, D. P. 2019. Expanding the definition of learning: From self to social to system. Medical Education, 53(6): 539-542.

Leedham-Green, K. E., Knight, A., \& Iedema, R. 2019. Intra- and interprofessional practices through fresh eyes: A qualitative analysis of medical students' early workplace experiences. BMC Medical Education, 19(1): 287.

Lloyd, D. M. 2009. The space between us: A neurophilosophical framework for the investigation of human interpersonal space. Neuroscience and Biobehavioral Reviews, 33(3): 297-304.

Sturmberg, J. P., \& Martin, C. M. 2008. Knowing - in medicine. Journal of Evaluation in Clinical Practice, 14(5): 767-770.

Wald, H. S. 2015. Professional identity (trans)formation in medical education: Reflection, relationship, resilience. Academic Medicine, 90(6): 701-706. 
Weinhold, J., Bornhauser, A., Hunger, C., \& Schweitzer, J. 2014. Triple efficacy. the heidelberg study on systems constellation. [dreierlei wirksamkeit. die heidelberger studie zu systemaufstellungen]. Heidelberg, Germany: Carl-Auer.

Witman, Y. 2014. What do we transfer in case discussions? the hidden curriculum in medicine. Perspectives on Medical Education, 3(2): 113-123.

Yazdani, S., Momeni, S., Afshar, L., \& Abdolmaleki, M. 2019. A comprehensive model of hidden curriculum management in medical education. Journal of Advances in Medical Education \& Professionalism, 7(3): 123-130. 
Tables and Figures

Table 1 Evaluation of the training by the students*

\begin{tabular}{|c|c|c|c|c|c|}
\hline & $\begin{array}{l}\text { I liked the } \\
\text { training }\end{array}$ & $\begin{array}{l}\text { The training } \\
\text { gave me } \\
\text { useful } \\
\text { insights or } \\
\text { help }\end{array}$ & $\begin{array}{c}\text { The } \\
\text { training } \\
\text { set-up was } \\
\text { clear to me }\end{array}$ & $\begin{array}{c}\text { The training } \\
\text { came ... }\end{array}$ & $\begin{array}{c}\text { How } \\
\text { satisfied } \\
\text { were you on } \\
\text { a scale of } 0 \\
\text { to } 100 ?\end{array}$ \\
\hline $\mathbf{N}$ & 223 & 223 & 223 & 213 & 220 \\
\hline 1-strongly disagree & $2.7 \%(6)$ & $4.9 \%(11)$ & $2.7 \%(6)$ & & \\
\hline 2 & $5.8 \%(13)$ & $5.4 \%(12)$ & $7.2 \%(16)$ & & \\
\hline 3 & $10.3 \%(23)$ & $10.3 \%(23)$ & $12.6 \%(28)$ & & \\
\hline $\begin{array}{l}\text { 4-neither agree nor } \\
\text { disagree }\end{array}$ & $17.0 \%(38)$ & $13.0 \%(29)$ & $13.5 \%(30)$ & & \\
\hline 5 & $27.4 \%(61)$ & $29.1 \%(65)$ & $22.9 \%(51)$ & & \\
\hline 6 & $30.0 \%(67)$ & $24.7 \%(55)$ & $22.9 \%(51)$ & & \\
\hline 7-strongly agree & $6.7 \%(15)$ & $12.6 \%(28)$ & $18.4 \%(41)$ & & \\
\hline Too early & & & & $3.3 \%(7)$ & \\
\hline On time & & & & $77.0 \%$ (164) & \\
\hline Too late & & & & $19.7 \%(42)$ & \\
\hline Mean (SD) & & & & & $67.6(16.0)$ \\
\hline
\end{tabular}

*Percentage (number) of students per answer category 
Table 2 Answers on the open questions, categorised

\begin{tabular}{ll}
\hline Question & $\mathrm{N}=72 *$
\end{tabular}

\begin{tabular}{lll}
\hline Do you have any suggestions for improvement? & $\%$ & N
\end{tabular}

Plan the training earlier in the year or the curriculum

$12.5 \%$

9

Make the training shorter

$13.9 \%$

10

Prepare the students better for the training

$22.2 \%$

16

Explain more about the training

$15.3 \%$

11

Have fewer students per training

$11.1 \% \quad 8$

Other comments

$25.0 \%$

18

What did you like about the workshop?

$$
\mathrm{N}=136^{*}
$$

Hear about other groups

$$
5.9 \%
$$

The atmosphere during the workshop

$11.8 \%$

16

The interactive, new method

$14.7 \%$

20

Visualisation of the social dynamics, new insights and change of

$54.4 \%$

74

perspective

Other comments

$13.2 \%$

18

*Number of students that answered the question; 


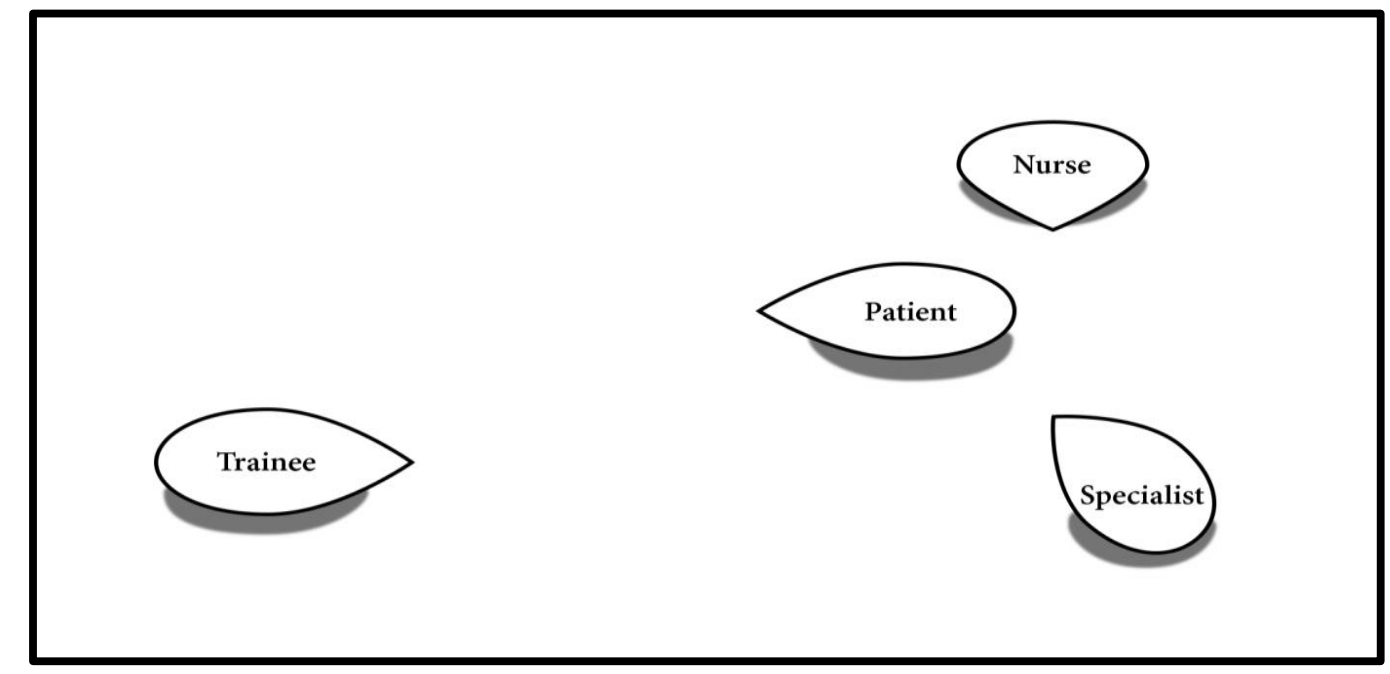

Figure 1 Schematic example of a spatial visualisation (a systemic constellation) of a medical social setting, with functions from this setting. The figures 'Trainee', 'Patient', 'Specialist' and 'Nurse' are persons representing these functions. The constellation shows the distance and positions (relative to each other) and interactions between these different functions in a spatial way. When representing one of the functions, a person can experience the perspective from this particular function in this social setting. Also, the other people present at the session and who have an observer view on the constellation, can collectively experience and reflect on the same constellation, i.e. they look at the same picture of the social setting together. This enables tacit knowledge about this social context to become voiced and discussed. For instance, some participants may express that they feel uncomfortable that the Trainee is far from the Patient, but acknowledge that the Trainee should not be too close either or obstruct the view of the Specialist. Others may notice that they, as Trainee, have difficulty with really seeing the Patient and would prefer to have the same view point as the Patient rather than looking in a different direction. This opened up a group reflection and discussion of their values and beliefs about the possible and preferred positions of a trainee in the medical context. 


\section{Figures}

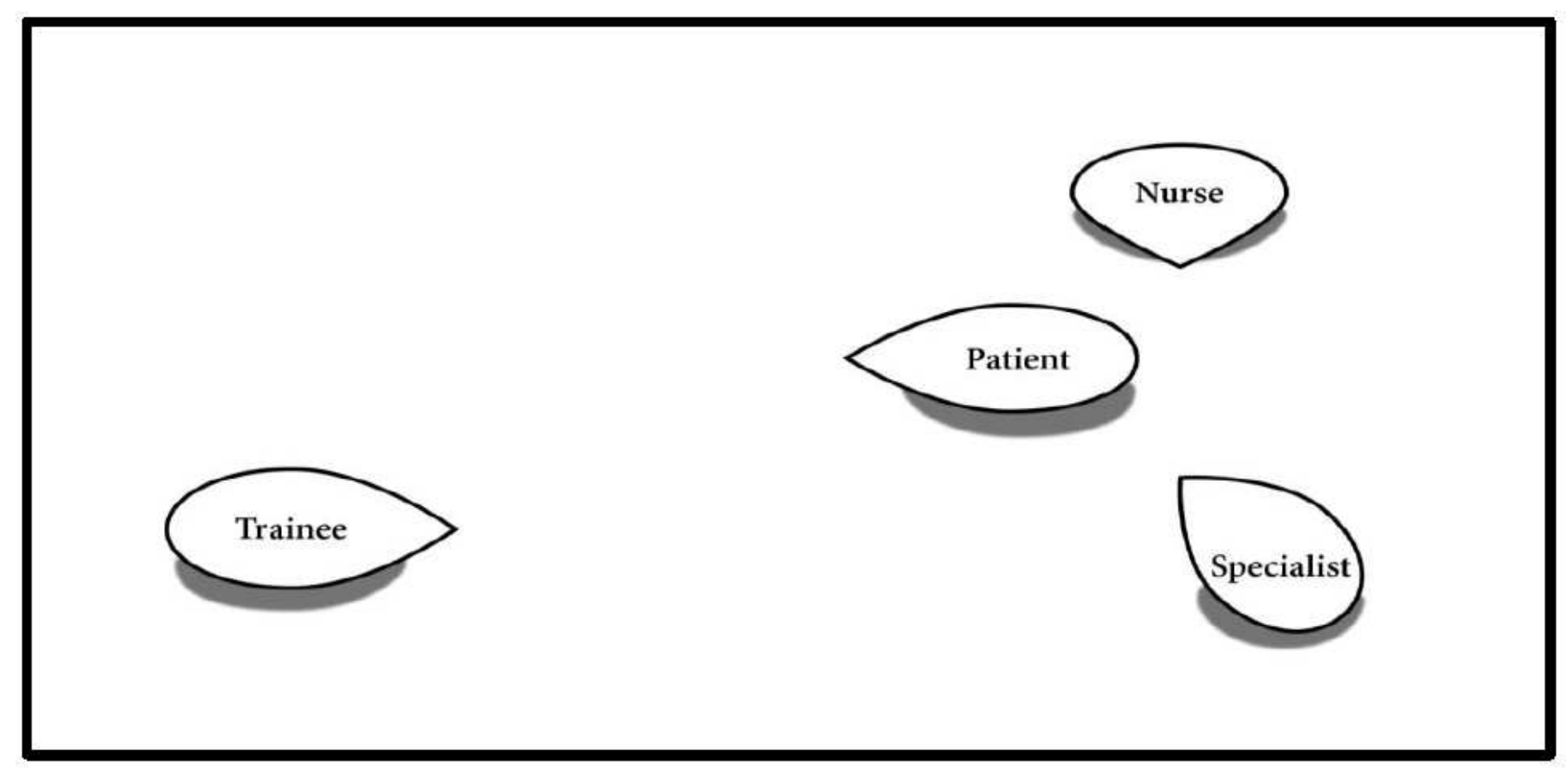

\section{Figure 1}

Schematic example of a spatial visualisation (a systemic constellation) of a medical social setting, with functions from this setting. The figures 'Trainee', 'Patient', 'Specialist' and 'Nurse' are persons representing these functions. The constellation shows the distance and positions (relative to each other) and interactions between these different functions in a spatial way. When representing one of the functions, a person can experience the perspective from this particular function in this social setting. Also, the other people present at the session and who have an observer view on the constellation, can collectively experience and reflect on the same constellation, i.e. they look at the same picture of the social setting together. This enables tacit knowledge about this social context to become voiced and discussed. For instance, some participants may express that they feel uncomfortable that the Trainee is far from the Patient, but acknowledge that the Trainee should not be too close either or obstruct the view of the Specialist. Others may notice that they, as Trainee, have difficulty with really seeing the Patient and would prefer to have the same view point as the Patient rather than looking in a different direction. This opened up a group reflection and discussion of their values and beliefs about the possible and preferred positions of a trainee in the medical context.

\section{Supplementary Files}

This is a list of supplementary files associated with this preprint. Click to download.

- ScholtensAppendix10utline20201114.pdf 
- ScholtensAppendix2Quest.20201114.pdf 